\section{Creation of Large Hybrid Populations Using Male-sterile Germplasm as the Female Parent in Jujube}

\author{
Fenfen Yan, Zhiguo Liu, and Mengjun Liu ${ }^{1}$ \\ Research Center of Chinese Jujube, Agricultural University of Hebei, \\ Baoding 071001, China
}

\section{Xingjuan Zheng, Zhi Luo, and Jiurui Wang ${ }^{1}$ \\ College of Forestry, Agricultural University of Hebei, Baoding 071001, China}

Additional index words. Chinese jujube, cross-combinations, hybrid population, male-sterile cultivar, SSR marker

\begin{abstract}
The establishment of large hybrid populations is the key basis to breeding new cultivars and genetic research, such as molecular mapping. However, it is extremely difficult to generate hybrid progeny using conventional artificial hybridization in Chinese jujube (Chinese date) (Ziziphus jujuba Mill.) because of its low fruit set of $\approx 0.01 \%$. The objective of this study was to create large hybrid populations in Chinese jujube using bona fide male-sterile germplasm as the female parent. Two male-sterile varieties that lacked viable pollen (JMS1 and JMS2) previously discovered by our research group and three male-fertile genotypes ('Xing16', 'Jiao5', and 'Wuhefeng') were used as female and male parents, respectively. Bee-aided controlled hybridization of five combinations was conducted from 2014 to 2016 . The results indicated that both JMS1 and JMS2 were stable male-sterile germplasm across the years examined. JMS2 showed more effective compatibility with the male parents tested than JMS1. A total of 7681 fruits were obtained from the five cross combinations, and 3120 of them contained seeds. The mean rate of the fruit with seed varied from $32.62 \%$ to $64.21 \%$, and the highest rate $(73.38 \%$ ) was obtained from the cross of JMS2 $\times$ 'Xing16' in 2016. A total of 831 seedlings were obtained and consisted of 602 from JMS2 $\times$ 'Xing16', 221 from JMS2 $\times$ 'Jiao5', two from JMS1 $\times$ 'Xing16', five from JMS1 $\times$ 'Wuhefeng', and one from JMS2 $\times$ 'Wuhefeng'. The 118 randomly selected progeny seedlings, including 96 from JMS2 $\times$ 'Xing16' and 22 from JMS2 $\times$ 'Jiao5', respectively, were identified to be authentic hybrids using SSR markers. Thus, JMS2 is a promising male-sterile female parent that possesses a good crosscompatibility and is free from the need for emasculation, embryo rescue, and hybrid identification. The largest hybrid population of 602 progeny was obtained in Chinese jujube using controlled hybridization. This study demonstrated the feasibility of a highly efficient crossbreeding approach using male-sterile germplasm as the female parent in Chinese jujube.
\end{abstract}

Hybrids may combine the advantages of two parents and display heterosis to meet the need for genetic improvement. To increase cross efficiency by avoiding the timeconsuming emasculation procedure, male sterility has been widely used to produce hybrids in many crops (Duan et al., 2015; Li et al., 2016; Liu et al., 2016) and horticultural plants (Bohra et al., 2016; Dey et al., 2013; Khan et al., 2013; Zhang et al., 2015). Many male-sterile genotypes have been used for hybridization in fruit trees such as citrus

\footnotetext{
Received for publication 6 Sept. 2017. Accepted for publication $23 \mathrm{Dec} .2017$.

This work was supported by the National Science Technology Support Program (2013BAD14B03) and Beijing Municipal Education Commission (CEFF-PXM2017_014207_000043).

F.Y. and Z.L. contributed equally to this work.

${ }^{1}$ Corresponding author. E-mail: wjrjujube@126. com or1mj1234567@aliyun.com.
}

cultivation (Liu et al., 2014). Therefore, it is of great importance for hybridization in Chinese jujube to find suitable germplasm resources that possess both male sterility and high embryo fertility to avoid the emasculation and embryo rescue steps when used as the female parent.

We previously discovered two malesterile varieties (JMS1 and JMS2) by screening natural germplasm sources and used them as the female parents to produce hybrids by controlled pollination (Sun et al., 2015; Wang et al., 2015). However, their characteristics of parthenocarpy, self-sterility, and cross-compatibility were not studied, and large hybrid populations have not yet been established. The aim of this study was to further investigate the hybridization-related traits of these two male-sterile germplasm sources and to use them as female parents to produce mass hybrids with high efficiency in Chinese jujube.

\section{Materials and Methods}

Materials. The two male-sterile germplasm sources JMS1 and JMS2 were used as the female parents, and two cultivars, Jiao5 (with high resistance to witches' broom disease) and Wuhefeng (with stoneless fruit), and one sour jujube (Ziziphus acidojujuba Cheng et Liu, ancestor close relative of Chinese jujube) genotype 'Xing 16' as the male parents for hybrid production. All of the materials tested were top-grafted onto 3-year-old rootstock 'Huizao' in 2012 in the 10th Regiment of Xinjiang Production and Construction Corps, Xinjiang, China.

Observation of pollen number and vitality. Flowers at the sepal flat stage in the middle of the bearing shoot were collected. The amount of pollen in each anther was determined by the counting chambers method (Zhang, 2001), and pollen viability was determined by the pollen germination method (Zhang, 1990).

Identification of parthenocarpy and parthenogenesis of male-sterile germplasm. The trees that possessed the male-sterile trait were covered under a nylon net before flowering, excluding other jujube genotypes and using honeybees as pollinators. Other management measures were the same as those used in the controlled hybridization. The number of fruits and the rate of fruits with seed were determined to identify the traits of parthenocarpy and parthenogenesis.

Bee-aided controlled hybridization. The crosses were conducted from 2014 to 2016 . To exclude unwanted pollinators, the adjacent trees of two parents were covered together with a white nylon net $2-3 \mathrm{~d}$ before flowering. A honeybee hive was placed into the net for pollination during the flowering season (Wang et al., 2015). Each area covered with netting contained six female parent trees and four male parent trees. To improve fruit setting, leaf fertilizer containing $2 \%$ boron and $3 \%$ monopotassium phosphate was sprayed once a week. 
Acquisition of progeny seedlings. Mature fruits were harvested, cleaned, and refrigerated at $4{ }^{\circ} \mathrm{C}$ for $60 \mathrm{~d}$. The seeds were obtained by discarding the fruit pulp and cracking the hard stone shell. The seeds were then soaked in 25 to $45{ }^{\circ} \mathrm{C}$ water for $24 \mathrm{~h}$ and then germinated at $28{ }^{\circ} \mathrm{C}$ for $36 \mathrm{~h}$. After that, they were sown in turf substrate in a greenhouse. The number of seedlings was determined $30 \mathrm{~d}$ later.

Hybrid identification of progeny seedlings by SSR markers. Genomic DNA was extracted from young leaves using the $\mathrm{CTAB}$ method, and polymerase chain reaction (PCR) amplifications were carried out in a $12.5-\mu \mathrm{L}$ reaction containing $0.5 \mu \mathrm{L}$ of 0.5 $\mathrm{ng} \cdot \mu \mathrm{L}^{-1}$ template DNA, $6.3 \mu \mathrm{L} 2 \times$ Taq PCR mix, $0.5 \mu \mathrm{M}$ of each primer, and $4.7 \mu \mathrm{L}$ $\mathrm{ddH}_{2} \mathrm{O}$. The PCR cycling profile consisted of an initial step of $94{ }^{\circ} \mathrm{C}$ for $5 \mathrm{~min}$; followed by 27 cycles of $94{ }^{\circ} \mathrm{C}$ for $30 \mathrm{~s}$, 50 to $55{ }^{\circ} \mathrm{C}$ (the annealing temperature changed depending on the primer) for $30 \mathrm{~s}$ and $72{ }^{\circ} \mathrm{C}$ for $30 \mathrm{~s}$, with a final extension step of $72^{\circ} \mathrm{C}$ for $10 \mathrm{~min}$. The products were analyzed by $8 \%(\mathrm{w} / \mathrm{v})$ denaturing polyacrylamide gels and silver staining (Fu et al., 2016; Xiao et al., 2015).

\section{Results}

Pollen fertility of the tested parent varieties. Throughout the three test years from 2014 to 2016, both male-sterile varieties used as female parents, 'JMS1' and 'JMS2', produced no viable pollen. This further confirmed the stability of their male sterility.

The pollen number per anther and the pollen vitality of the three male parent genotypes, 'Wuhefeng', 'Xing16', and 'Jiao5', varied with the years and differed significantly between them (Table 1). 'Wuhefeng' and 'Xing16' had a much larger pollen number per anther, 35,926 and 36,296 in 2016, respectively, compared with 'Jiao5'. The pollen viability of 'Jiao5' was also lower (Table 1).

Identification of parthenocarpy and parthenogenesis of the two male-sterile varieties used as female parents. Several of the fruits were obtained from JMS1 and JMS2 under the conditions of both selfpollination and cross-pollination (Table 2). However, the rates of fruit with seed varied significantly under the different pollination conditions (Table 2). The rate was $26.31 \%$ to $50.22 \%$ for cross-pollination. No seed was formed in the fruits that had been selfpollinated. The rate of fruit with seeds changed slightly between 2015 and 2016, but it was much higher in JMS2 than JMS1. Based on these data, JMS1 and JMS2 possess high-level parthenocarpy but no parthenogenesis. Thus, all the seeds from JMS1 and JMS2 should be hybrids.

The cross-compatibility of five combinations using male-sterile cultivars as female parents. A total of 7681 fruits and 3120 seeds were obtained from five cross combinations using JMS2 and JMS1 as the female parents from 2014 to 2016 (Table 3). Of these, 2230 seeds were from JMS2 × 'Xing16' and 787 from
JMS2 'Jiao5' with a mean rate of fruit with seed of $64.21 \%$ and $32.62 \%$, respectively. In contrast, the mean rates of fruit with seed of JMS2 $\times$ 'Wuhefeng' and JMS1 $\times$ 'Wuhefeng' were less than $5 \%$. In the combinations of JMS2 $\times$ 'Xing16' and JMS2 $\times$ 'Jiao5', the number of fruits and the rate of fruit with seed increased noticeably between 2014 and 2016 and were proportional to the age of the trees and the experience of the operators. The rate of fruit with seed in JMS2 $\times$ 'Xing 16' reached 73.38\% in 2016, which was greater than that observed previously. With the same male parent, JMS $2 \times$ 'Xing 16' produced substantially more fruits and seeds than JMS1 $\times$ 'Xing16'. It was demonstrated that JMS2 has very high compatibility

with 'Xing16' and 'Jiao5', and both JMS2 and JMS1 were almost incompatible with 'Wuhefeng'. Based on both fruiting ability and crosscompatibility, JMS2 $\times$ 'Xing16' is the best cross combination, followed by JMS2 $\times$ 'Jiao5'.

In addition, the number of fruit and seed obtained from the male parents were investigated taking them as female parents and the male-sterile female parents (JMS1 and JMS2) as the male parents (Table 4). The results indicated that 'Jiao5' and 'Wuhefeng' are self-sterile and do not produce seeds. 'Xing16' showed a low level of selfcompatibility. All three of the male parents had a very high level of parthenocarpy, and

Table 1. Pollen number and viability of three male parent genotypes.

\begin{tabular}{lccccc}
\hline & \multicolumn{2}{c}{2015} & & 2016 \\
\cline { 2 - 3 } \cline { 5 - 6 } Cultivar & Pollen no. per anther & Pollen viability (\%) & & Pollen no. per anther & Pollen viability (\%) \\
Xing16 & $25,793 \pm 2,291 \mathrm{a}^{z}$ & $37.52 \pm 14.81 \mathrm{a}$ & & $35,926 \pm 6,032 \mathrm{a}$ & $31.55 \pm 9.31 \mathrm{a}$ \\
Wuhefeng & $18,889 \pm 2,650 \mathrm{~b}$ & $44.87 \pm 16.82 \mathrm{a}$ & & $36,296 \pm 1,945 \mathrm{a}$ & $18.44 \pm 5.23 \mathrm{~b}$ \\
Jiao5 & $15,926 \pm 1,411 \mathrm{~b}$ & $9.81 \pm 4.18 \mathrm{~b}$ & & $23,852 \pm 3,434 \mathrm{~b}$ & $20.82 \pm 9.95 \mathrm{~b}$ \\
\hline
\end{tabular}

${ }^{\mathrm{z}}$ Means followed by different letters were significantly different in columns according to Duncan's multiple range tests $(P \leq 0.05)$.

Table 2. The rate of fruit with seed in JMS1 and JMS2.

\begin{tabular}{lcccccc}
\hline & & \multicolumn{2}{c}{ No. of fruits } & & \multicolumn{2}{c}{ Rate of fruit with seed (\%) } \\
\cline { 3 - 4 } Cultivar & Yr & Cross-pollination & Self-pollination & & Cross-pollination & Self-pollination \\
\hline \multirow{2}{*}{ JMS1 } & 2015 & 120 & 33 & & $34.18 \mathrm{a}^{z}$ & 0 \\
& 2016 & 65 & 100 & & $26.31 \mathrm{a}$ & 0 \\
JMS2 & 2015 & 241 & 323 & & $50.22 \mathrm{a}$ & 0 \\
& 2016 & 517 & 200 & & $49.95 \mathrm{a}$ & 0
\end{tabular}

$\overline{{ }^{\mathrm{z}} \text { Means followed by different letters were significantly different in column according to Duncan's multiple }}$ range tests $(P \leq 0.05)$.

Table 3. Fruits and seeds obtained from five cross combinations.

\begin{tabular}{|c|c|c|c|c|c|c|c|}
\hline & & $\begin{array}{l}\text { JMS2 } \times \\
\text { Xing } 16\end{array}$ & $\begin{array}{l}\text { JMS2 } \times \\
\text { Jiao } 5\end{array}$ & $\begin{array}{c}\text { JMS2 } \times \\
\text { Wuhefeng }\end{array}$ & $\begin{array}{l}\text { JMS1 } \times \\
\text { Xing16 }\end{array}$ & $\begin{array}{c}\text { JMS1 } \times \\
\text { Wuhefeng }\end{array}$ & Total \\
\hline \multirow[t]{3}{*}{2016} & No. of fruits & 2,303 & 1,732 & 623 & 374 & 244 & 5,276 \\
\hline & No. of seeds & 1,690 & 654 & 1 & 8 & 6 & 2,359 \\
\hline & $\begin{array}{l}\text { Rate of fruits } \\
\text { with seed (\%) }\end{array}$ & 73.38 & 37.76 & 0.16 & 2.14 & 2.46 & - \\
\hline \multirow[t]{3}{*}{2015} & No. of fruits & 841 & 435 & 122 & 84 & 7 & 1,489 \\
\hline & No. of seeds & 517 & 52 & 0 & 4 & 4 & 577 \\
\hline & $\begin{array}{l}\text { Rate of fruits } \\
\text { with seed (\%) }\end{array}$ & 61.47 & 11.95 & 0.00 & 4.76 & 57.14 & - \\
\hline \multirow[t]{3}{*}{2014} & No. of fruits & 329 & 246 & 174 & 116 & 51 & 916 \\
\hline & No. of seeds & 23 & 81 & 1 & 74 & 5 & 184 \\
\hline & $\begin{array}{l}\text { Rate of fruits } \\
\text { with seed (\%) }\end{array}$ & 6.99 & 32.93 & 0.57 & 63.79 & 9.80 & - \\
\hline \multirow[t]{2}{*}{ Total } & No. of fruits & 3,473 & 2,413 & 919 & 574 & 302 & 7,681 \\
\hline & No. of seeds & 2,230 & 787 & 2 & 86 & 15 & 3,120 \\
\hline \multicolumn{2}{|c|}{$\begin{array}{l}\text { Mean rate of fruits with } \\
\text { seed }(\%)\end{array}$} & 64.21 & 32.62 & 0.22 & 14.98 & 4.97 & 40.62 \\
\hline
\end{tabular}

$-=$ not calculated

Table 4. Fruits and seeds obtained from the tested male parents when treated as female parents

\begin{tabular}{|c|c|c|c|c|c|}
\hline \multirow[b]{2}{*}{ Cultivar } & \multirow[b]{2}{*}{$\mathrm{Yr}$} & \multicolumn{2}{|c|}{ Using male-sterile genotype as the male parent } & \multicolumn{2}{|c|}{ Natural cross-pollination } \\
\hline & & No. of fruits & Rate of fruit with seed (\%) & No. of fruits & $\begin{array}{c}\text { Rate of fruit } \\
\text { with seed }(\%)\end{array}$ \\
\hline \multirow[t]{2}{*}{ Xing16 } & 2014 & 392 & $2.37 \pm 2.49$ & 180 & $40.02 \pm 5.85 \mathrm{a}^{\mathrm{z}}$ \\
\hline & 2015 & 137 & $1.53 \pm 0.71$ & 185 & $34.92 \pm 14.09 \mathrm{a}$ \\
\hline \multirow{2}{*}{ Jiao5 } & 2014 & 370 & 0 & 62 & $5.00 \pm 5 b$ \\
\hline & 2015 & 171 & 0 & 138 & $5.38 \pm 3.8 b$ \\
\hline \multirow[t]{2}{*}{ Wuhefeng } & 2014 & 688 & 0 & 355 & $1.28 \pm 0.63 \mathrm{~b}$ \\
\hline & 2015 & 130 & 0 & 650 & $0.28 \pm 0.25 \mathrm{~b}$ \\
\hline
\end{tabular}

${ }_{\mathrm{z}}$ Means followed by different letters were significantly different in column according to Duncan's multiple range tests $(P \leq 0.05)$. 
cross-pollination increased the formation of seed set.

Hybrid identification of the offspring using male-sterile cultivar as female parents. The seeds from five cross combinations produced a total of 831 seedlings (Fig. 1): 602 from JMS2 × 'Xing16', 221 from JMS2 $\times$ 'Jiao5', two from JMS1 $\times$ 'Xing 16', five from JMS1 $\times$ 'Wuhefeng', and one from JMS $2 \times$ 'Wuhefeng' (Table 5). Analysis with the primer JSSR 311 indicated that the male and female parents displayed different bands, and their progeny had two bands from both parents (Figs. 2 and 3). A total of 118 progeny including 96 from JMS2 $\times$ 'Xing16' and 22 from JMS2 $\times$ 'Jiao5' were randomly selected, and all of them were identified as authentic hybrids using SSR markers, which further demonstrated the traits of male sterility and lack of parthenogenesis in JMS1 and JMS2. As a result, two large hybrid populations from JMS2 $\times$ 'Xing 16' (602 individuals) and JMS2 $\times$ 'Jiao5' (221 individuals) were established for the first time.

\section{Discussion}

The authenticity of the hybrids from cross combinations designed for special purposes should be ensured in crossbreeding. Progeny from several cross combinations of Chinese jujube had been identified as true hybrids using molecular markers such as SSR and AFLP (Lu et al., 2005; Wang et al., 2012). If the male-sterile varieties with no parthenogenesis were used as the female parents, all of the seeds from them should be authentic hybrids without the need of identification. This study conclusively determined that both JMS2 and JMS1 have traits of stable male sterility, lack of parthenogenesis, and possess good cross-compatibility. In addition, all of their progeny that were randomly selected were verified as authentic hybrids by SSR markers. Thus, all of the seeds obtained from the hybridization using JMS2 or JMS1 as female parents could be unequivocally used as authentic hybrids for large-scale crossbreeding in Chinese jujube. JMS2 was more effective at producing fruit and had a higher rate of fruit with seed than JMS1. As a result, JMS2 appears to be a very promising female parent of Chinese jujube because of its advantages of eliminating the need for labor-intensive emasculation and hybrid identification, its strong compatibility with a wide range of male parents, and its high efficiency at producing hybrid seedlings.

The compatibility between parents is a key factor in crossbreeding. The present study indicated that 'JMS2' and 'JMS1' are highly compatible with 'Xing 16' and 'Jiao5' but both of them were incompatible with 'Wuhefeng', whereas 'Jiao5' and 'Wuhefeng' were self-incompatible. Yan et al. $(2009,2010)$ also reported that many cultivars of Chinese jujube are self-sterile. Thus, these results indicate that the traits of selfcompatibility, self-incompatibility, crosscompatibility, and cross-incompatibility all

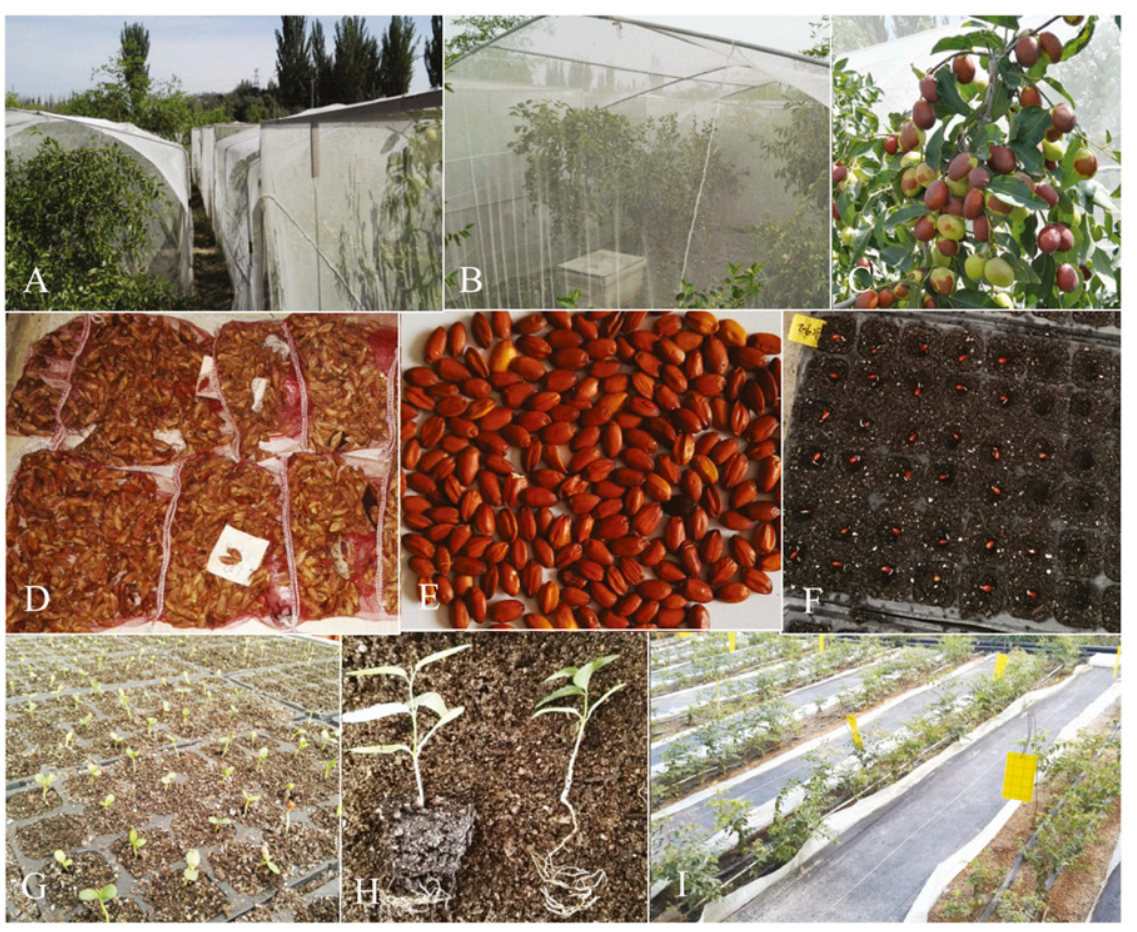

Fig. 1. Hybrid production from JMS2 $\times$ Xing16. (A) Controlled hybridization. (B) Bee-aided pollination. (C) Bearing of JMS2 under controlled hybridization. (D and E) Stones and seeds from JMS2 fruits.

(F-I) Sowing of JMS2 seeds and the process of seedling formation in greenhouse.

Table 5. Hybrid population obtained in 2015 and 2016

\begin{tabular}{|c|c|c|c|c|c|c|c|}
\hline & & $\begin{array}{l}\text { JMS2 } \times \\
\text { Xing16 }\end{array}$ & $\begin{array}{l}\text { JMS } 2 \times \\
\text { Jiao5 }\end{array}$ & $\begin{array}{c}\text { JMS } 2 \times \\
\text { Wuhefeng }\end{array}$ & JMS1 $\times$ Xing 16 & $\begin{array}{c}\text { JMS1 } \times \\
\text { Wuhefeng }\end{array}$ & Total \\
\hline \multirow[t]{3}{*}{$\overline{2016}$} & No. of seeds & 1,004 & 480 & 1 & 8 & 6 & 1,499 \\
\hline & Total seedling & 421 & 197 & 1 & 1 & 3 & 623 \\
\hline & $\begin{array}{l}\text { Rate of total } \\
\quad \text { seedling (\%) }\end{array}$ & 41.93 & 41.04 & 100.00 & 12.50 & 50.00 & - \\
\hline \multirow[t]{3}{*}{2015} & No. of seeds & 452 & 47 & 0 & 4 & 4 & 507 \\
\hline & Total seedling & 181 & 24 & 0 & 1 & 2 & 208 \\
\hline & $\begin{array}{l}\text { Rate of total } \\
\text { seedling (\%) }\end{array}$ & 40.04 & 51.06 & 0.00 & 25.00 & 50.00 & - \\
\hline \multirow{2}{*}{ Total } & No. of seeds & 1,456 & 527 & 1 & 12 & 10 & 2,006 \\
\hline & Total seedling & 602 & 221 & 1 & 2 & 5 & 831 \\
\hline \multicolumn{2}{|c|}{$\begin{array}{l}\text { Mean rate of total } \\
\text { seedling }(\%)\end{array}$} & 41.35 & 41.94 & 100.00 & 16.67 & 50.00 & - \\
\hline
\end{tabular}

seedling (\%)

$-=$ not calculated.

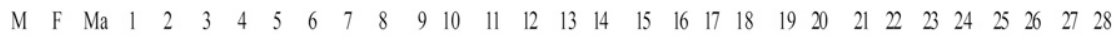

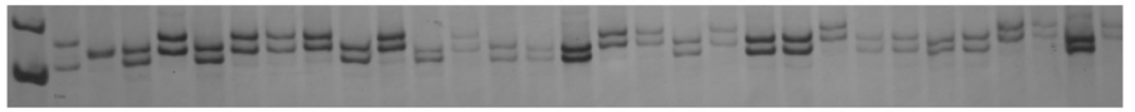

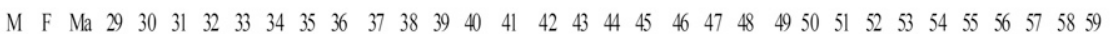

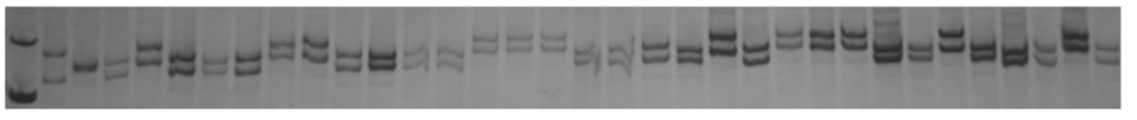

M F Ma $6061626364656667686970717273 \quad 74757677 \quad 787980818283848586 \quad 878889909192 \quad 93 \quad 949596$

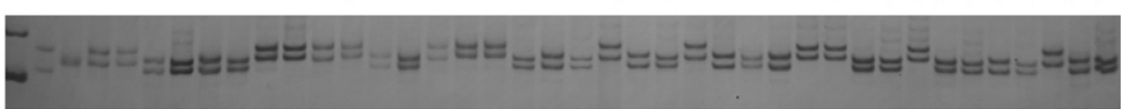

Fig. 2. Molecular identification of hybrids from JMS2 $\times$ Xing16 using primer JSSR $311 . \mathrm{M}=$ Marker; $\mathrm{F}=\mathrm{JMS} 2 ; \mathrm{Ma}=$ Xing 16; $1-96=$ Progenies.

exist in Chinese jujube. An inhibitory factor exists in the pistil stigma that could hinder the germination of pollen and induce callose

deposition (Zhao et al., 2012). The mechanisms behind these reproductive biology phenomena in Chinese jujube need to be studied further. 


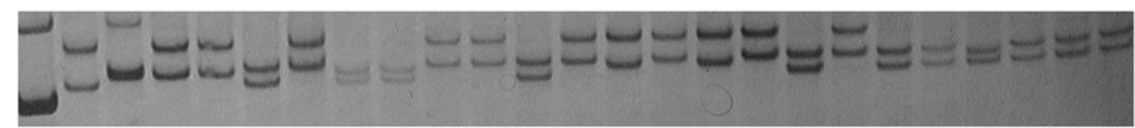

Fig. 3. Molecular identification of hybrids from JMS2 $\times$ 'Jiao5' using primer JSSR 311. M = Marker; $\mathrm{F}=\mathrm{JMS} 2 ; \mathrm{Ma}=\mathrm{Jiao5}, 1-22=$ Progenies with two bands transmitted respectively from female and male parents.

To discover more feasible cross combinations, it is critical to investigate the crosscompatibility of JMS2 and JMS1 with superior varieties that have a high potential to serve as the male parent in hybridization. In addition, varieties with self-sterility could also be used as female parents for such traits as male-sterile germplasm to avoid the time-consuming emasculation procedure in crossbreeding.

\section{Literature Cited}

Bohra, A., U. Jha, P. Adhimoolam, D. Bisht And, and N. Singh. 2016. Cytoplasmic male sterility (CMS) in hybrid breeding in field crops. Plant Cell Rep. 35:967-993.

Dey, S.S., R. Bhatia, S.R. Sharma, C. Parkash, and A.K. Sureja. 2013. Effects of chloroplast substituted Ogura male sterile cytoplasm on the performance of cauliflower (Brassica oleracea var. botrytis L.) F1 hybrids. Scientia Hort. 157:45-51.

Donoso, J.M., I. Eduardo, R. Picañol, I. Batlle, W. Howad, M.J. Aranzana, and P. Arús. 2015. High-density mapping suggests cytoplasmic male sterility with two restorer genes in almond $x$ peach progenies. Hort. Res. 2:15016.

Duan, Z.B., C.C. Shen, Q.Y. Li, G.Z. Lu, Y.J. Ni, D.Y. Yu, and J.S. Niu. 2015. Identification of a novel male sterile wheat mutant dms conferring dwarf status and multi-pistils. J. Integr. Agr. 14:1706-1714.

Fu, P.C., Y.Z. Zhang, H.Y. Ya, and Q.B. Gao. 2016. Characterization of SSR genomic abundance and identification of SSR markers for population genetics in Chinese jujube (Ziziphus jujuba Mill.). PeerJ 10:1735.

Guo, W.W., D. Prasad, Y.J. Cheng, P. Serrano, X.X. Deng, and J.W. Grosser. 2004. Targeted cybridization in citrus: Transfer of Satsuma cytoplasm to seedy cultivars for potential seedlessness. Plant Cell Rep. 22:752-758.
He, T.M. 2012. Analysis of free amino acids catalase activity in floral buds and anthers in male-sterile 'Xinli No.7' pear. J. Fruit Sci. 29:338-342.

James, E.R., F.F. Michael, C.B.C. Quentin, B Diane, and W.C. Mark. 2000. A phylogenetic analysis of Rhamnaceae using rbcL and trnL-F plastid DNA sequences. Amer. J. Bot. 87:1309-1324.

Khan, M.M.R., M. Hasnunnahar, M. Lwayoshi, and S. Isshiki. 2013. Pollen and seed fertility of the male fertile lines having the fertility restorer gene in three CMS systems of eggplant. Scientia Hort. 157:39-44.

Li, Q.L., D.B. Zhang, M.G. Chen, W.Q. Liang, J.J Weia, Y.P. Qi, and Z.A. Yuan. 2016. Development of japonica photo-sensitive genic male sterile rice lines by editing carbon starved anther using CRISPR/Cas9. J. Genet. Genomics 43:415-419.

Liu, M. 2006. Chinese jujube: Botany and horticulture. Hort. Rev. 32:229-298.

Liu, M., P. Liu, and G. Liu. 2013. Advances of research on germplasm resources of Chinese jujube. Acta Hort. 993:15-20.

Liu, M.J., J.R. Wang, P. Liu, M.J. Lin, J. Xiao, Z.G Liu, and X.C. Sun. 2014. Design and practice of emasculation-free cross breeding in Chinese jujube. Acta Hort. Sinica 41:1495-1502.

Liu, M.J., J.R. Wang, P. Liu, J. Zhao, Z.H. Zhao, L. Dai, X.S. Li, and Z.G. Liu. 2015. Historical achievements and frontier advances in the production and research of Chinese jujube (Ziziphus jujuba) in China. Acta Hort. Sinica 42:1683-1698.

Liu, Q.Z., B.B. Zhang, L. Qi, Z. Zhang, and J.M. and pollen abortion in two types of grapes. J. Fruit Sci. 27:514-520.

Liu, W.Q., Q.H. Meng, L.S. Weng, J. Peng, Y.L. Xiao, J.G. Yu, Z.L. Yi, and G.Y. Xiao. 2016. A comparative study of two-line early season hybrid rice with lepidopteran resistance. Field Crops Res. 187:107-112. Tao. 2010. Cytological study of male sterility
Lu, J.Y., Y.M. Mao, L.Y. Shen, S.Q. Peng, and M. Liu. 2005. Application of AFLP markers for identification of hybrids from open pollinated Dongzao (Zizyphus jujuba Mill.) progenies. Acta Hort. Sinica 32:680-683.

Sun, X.C., J.R. Wang, L. Dai, J. Zhao, and M.J. Liu. 2015. Fertility of male-sterile germplasms under controlled hybridzation and molecular identification of hybrids by SSR in Chinese jujube. J Agr. Univ. Hebei 38:40-43.

Wang, J.R., X.M. Cui, L. Dai, P. Liu, J. Zhao, and M.J. Liu. 2015. Hybridization using a new male-sterile germplasm as the female parents in Chinese jujube. Korean J. Hort. Sci. Technol. 33:396-402.

Wang, S.Q., S.Z. Tang, D.C. Kong, R.P. He, H.B Liu, L.Y. Ma, J. Liu, Z. Wang, Y.Y. Li, L.Y. Shen, and X.M. Pang. 2012. Application of SSR markers for the identification of paternal parent for the seedlings of Chinese jujube. Acta Hort. Sinica 39:2133-2141.

Xiao, J., J. Zhao, M.J. Liu, P. Liu, L. Dai, and Z.H. Zhao. 2015. Genome-wide characterization of simple sequence repeat (SSR) loci in Chinese jujube and jujube SSR primer transferability. PLoS One 10:e127812.

Yan, C., P. Liu, M.J. Liu, J.R. Wang, L. Dai, D.K. Li, and D.C. Kong. 2009. Characteristics of fruiting and fertility of different cultivars of Ziziphus jujuba Mill. J. Plant Genet. Resources 10:121-125.

Yan, C., P. Liu, M.J. Liu, J.R. Wang, D.C. Kong, and D.K. Li. 2010. The influencing factor of fruiting characteristics of Ziziphus jujuba. Scientia Silvae Sinicae 46:78-86.

Yao, S. 2013. Past, present, and future of jujubesChinese dates in the United States. HortScience 48:672-680

Zhao, D., F. Wang, X.M. Zhao, F.M. Yang, L. Yu, and J. Niu. 2012. Studies of cross compatibility and fecundity on part of diospyros. Acta Hort. Sinica 39:2229-2237.

Zhang, W.C. 2001. Methods in fruit studies (in Chinese). 3rd ed. China Agriculture Press, Beijing, China.

Zhang, X.F., B. Chen, L.Y. Zhang, L.L. Zhang, X.H. Chen, H. Zhao, and S.S. Geng. 2015. Identification of proteins associated with cytoplasmic male sterility in pepper (Capsicum annuиm L.). S. Afr. J. Bot. 100:1-6.

Zhang, Z.L. 1990. Experiment guide of plant physiology (in Chinese). 3rd ed. Higher Education Press, Beijing, China. 